\title{
Synthesis of a biobased antioxidant additive for diesel fuel
}

\author{
Chikh Sabrina ${ }^{1}$, Pemanos Yelda Bakoz ${ }^{2}$, Zourane Tinhinane ${ }^{1}$, Hamada Boudjema ${ }^{1, ~ * ~}$ \\ ${ }^{1}$ Laboratory of Petrochemical synthesis, Faculty of Hydrocarbons and Chemistry, University M'hamed Bouguara-Boumerdes, Algeria \\ ${ }^{2}$ Depatment of Chemistry, College of Science, University of ZaKho, Kurdistan Rigion, Iraq
}

\section{Email address:}

bou. hamada@yahoo.fr (H. Boudjema)

\section{To cite this article:}

Chikh Sabrina, Pemanos Yelda Bakoz, Zourane Tinhinane, Hamada Boudjema. Synthesis of a Biobased Antioxidant Additive for Diesel Fuel. American Journal of Applied Chemistry. Vol. 2, No. 1, 2014, pp. 10-14. doi: 10.11648/j.ajac.20140201.13

\begin{abstract}
In this study, our objective is to synthesize a biobased antioxidant additive for Diesel fuel during the storage. Our choice was made particularly on the olive oil as raw material because of its oleic acid content which is more to $75 \%$. The processes involved were epoxidation of oleic acid of the olive oil, opening of the oxirane ring, and esterification. The structures of the products were confirmed by FTIR. To test the effectiveness of our biobased antioxidant additive, we carried out Accelerated Oxidation Test - AOT on diesel without additive (blank) and diesel with additive with various concentrations: 2000,4000 and $6000 \mathrm{ppm}$. The oxidative degradation of diesel with or without antioxidants was investigated by UV-visible spectroscopy was used to monitor the changes using peroxide value. A remarkable stability of diesel with antioxidant additive comparing with the blank confirms the inhibition of the oxidation phoneme and thus of the good efficiency of antioxidant additive from the optimal concentration of 2000ppm.
\end{abstract}

Keywords: Biobased Additive, Antioxidant, Diesel Fuel, Peroxide Value, Accelerated Oxidation Test

\section{Introduction}

Our work falls under a set of themes which answers a major series of restrictions related to the use of the various fuels, requirements are emitted each year such as the toxicity and the biodegradation as of the latter. The progressive replacement of the petroleum products by other alternate products is planned to solve the double problems of availability of the energy and the environmental protection $[1,2]$. The biomass seems a source of promising energy for petrochemical industry and the refining, in particular when it is transformed into biofuels or bioadditives usable directly in the traditional engine combustion. Indeed, to replace products resulting from oil resources by biobased compounds makes it possible to reduce the consumption of fossil resources and the gas emissions for purpose of greenhouse at the end of the lifetime of the products [3, 4].

Vegetable oils are an abundant natural resource, varied, not very expensive and available. In addition, they present an interesting functionality and are not harmful for the man or the environment [4].Our choice was made particularly on the olive oil because of its wealth of oleic acid.

Our objective is to synthesize an additive for Diesel fuel starting from a vegetable oil, and we carried an interest particular to the antioxidant additives having like principal function to inhibit the formation of peroxides.

During storage, Diesel fuel can be extremely sensitive to oxidation and thermal degradation. In the presence of oxygen, the Diesel is likely to undergo, even at ambient temperature, a process of oxidation which leads to the formation of viscous products called usually gums [5]. Additives for petroleum products are substances that are mixed with lubricants and fuels with well-defined proportions to enhance their natural properties or give their new physical or chemical properties $[5,6]$. The antioxidant additives guarantee the storage stability by avoiding the formation of sediments and of gums in the tanks and the latter can then clog the filters. They are also called inhibitors of oxidation [5].

\section{Materials and Methods}

\subsection{Materials}

The olive oil used as raw material for the synthesis and the fractions of the diesel were characterized according to standards' in force. Formic acid (88\%) was obtained from Fisher Scientific. All other chemicals, reagents and solvents 
were obtained from Aldrich Chemical. All materials were used without further purification. All organic extracts were dried using anhydrous magnesium sulfate (Aldrich Chemical).

\subsection{Characterization}

Fourier transform infrared (FTIR) spectra were recorded on a BRUKER Alpha-T Spectrophotometer.

UV-vis absorption spectra were recorded using a SHIMADZU U-1800 spectrophotometer, All data were collected in the range of $200-800 \mathrm{~nm}$.

\subsection{Synthesis of Triester}

\subsubsection{Epoxidation Oleic Acid of the Olive Oil (EOA)}

Hydrogen peroxide solution $(30 \%, 8.0 \mathrm{~mL})$ was added slowly into a stirred solution of oleic acid (OA) $(90 \%, 15 \mathrm{~g})$ in formic acid $(88 \%, 14 \mathrm{~mL})$ at $4^{\circ} \mathrm{C}$ (ice bath) and the combined reaction was allowed to proceed at room temperature with vigorous stirring $(900 \mathrm{rpm})$ until the formation of a white, powdery solid (about 2-5 h). The solid was collected via vacuum filtration, washed with $\mathrm{H}_{2} \mathrm{O}$ (chilled, $3 \times 10 \mathrm{~mL}$ ), and placed under high vacuum for $12 \mathrm{~h}$, yielding deoxidized oleic acid (EOA) as a colorless, powdery solid.

\subsubsection{Synthesis of Monoester}

\section{Hydroxy-10-acyloxyoctadecanoic Acid (HYAODA)}

To a mixture of EOA (31 g), $5 \mathrm{~g}$ of p-toluenesulfonic acid (PTSA) and toluene $(70 \mathrm{~mL})$, fatty acids $(6 \mathrm{~g})$ were added during $1.5 \mathrm{~h}$. the mixture was kept in a thermostat for $1.5 \mathrm{~h}$ in order to keep the reaction mixture temperature under $70-80^{\circ} \mathrm{C}$. The reaction mixture was subsequently heated to 90-100 ${ }^{\circ} \mathrm{C}$ and refluxed for $3 \mathrm{~h}$. After the reaction termination, the heating was stopped and the mixture was left to stand overnight at ambient room temperature. The mixture was washed with the water next day. The organic layer was dried over anhydrous magnesium sulfate and the solvent was removed using the vacuum evaporator.

\subsubsection{Synthesis of Diester Butyl \\ 9-Hydroxy-10-Acyloxyoctadecanoate (BHYAOD)}

Sulfuric acid (conc. H2SO4, $10 \mathrm{~mol} \%$ ) was added into a stirred suspension of HYAODA (3.35 mmol) in $n$ - butanol $(3.35 \mathrm{~mL})$. The suspension was heated with stirring at $60{ }^{\circ} \mathrm{C}$ for $10 \mathrm{~h}$. Hexanes $(5 \mathrm{~mL})$ was then added. The solution was washed with $\mathrm{NaHCO} 3$ (sat. aq., 1 x $0.5 \mathrm{~mL})$ and brine $(2 \times 1$ $\mathrm{mL}$ ), dried using $\mathrm{MgSO}$, filtered, concentrated in vacuo and placed for $6 \mathrm{~h}$ under vacuum to yield the desired product.

\subsubsection{Synthesis of Triesters Butyl 9-(octadecanoyloxy) 10-(acyloxy) Octadecanoate (BOOAOD)}

Oleic acid (5 g) was added to a solution of diesters Butyl 9-hydroxy-10-acyloxyoctadecanoate ( $5 \mathrm{~g}$ ) and sulfuric acid $(10 \%)$ in a 2-neck round-bottomed flask equipped with a magnetic stir bar at room temperature; The mixture was heated to $50^{\circ} \mathrm{C}$; then the reaction mixture was refluxed with stirring for $10 \mathrm{~h}$. After the reaction was transferred to a separatory funnel, the lower aqueous phase was removed, and hexane $(20 \mathrm{~mL})$ was added to the upper oily phase. The organic phase was then washed with $\mathrm{NaHCO} 3$ (sat. aq., $2 \times$ $5 \mathrm{~mL})$ and brine $(2 \times 5 \mathrm{~mL})$, dried over anhydrous magnesium sulfate, filtered, concentrated in vacuo, and placed under high vacuum for $6 \mathrm{~h}$ to provide the triesters as clear oils, which were stored over molecular sieves to mitigate potential hydrolysis.

\subsection{Accelerated Oxidation Test-AOT}

Accelerated oxidation test (AOT) was carried out in an oxidation apparatus with base in the Rancimat method [6, 7]. The Diesel samples were placed in a $100 \mathrm{~mL}$ vessel of glass, kept at a constant temperature $\left(150{ }^{\circ} \mathrm{C}\right)$, in the presence of air atmosphere $(21 \%$ oxygen) $[8,9]$.The oxidation process was monitored by UV-vis spectroscopy and by peroxide value determination, where the samples were collected at intervals of 1 hour and analyzed [10].
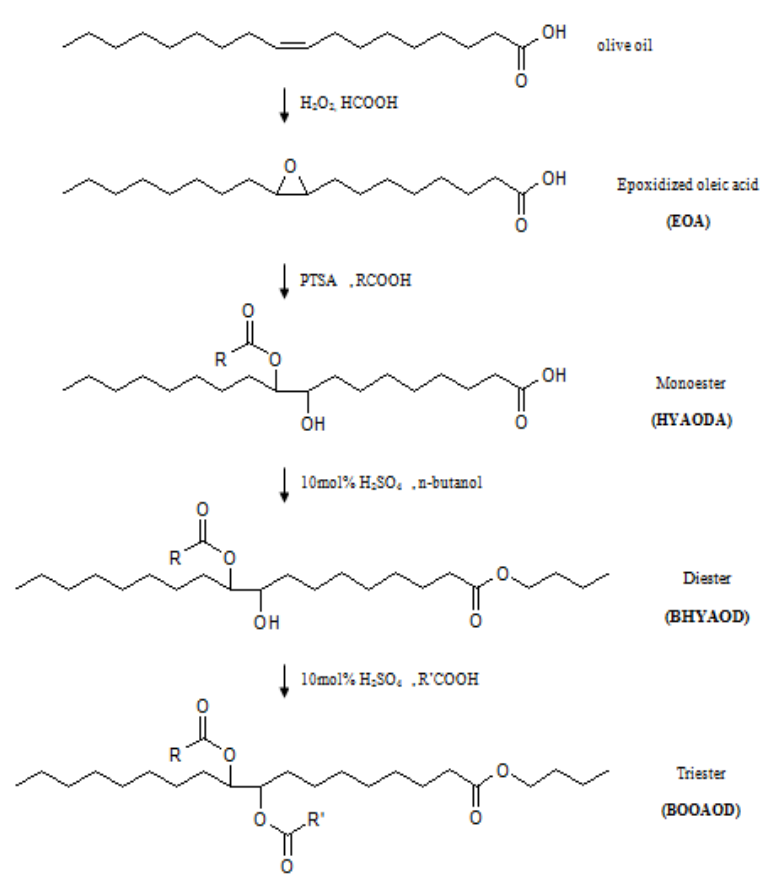

Figure 1. Triesters formation. RCOOH: $\mathrm{CH}_{3}\left(\mathrm{CH}_{2}\right)_{14} \mathrm{COOH} ; \mathrm{R}^{\prime} \mathrm{COOH}$ : $\mathrm{CH}_{3}\left(\mathrm{CH}_{2}\right)_{7} \mathrm{CH}=\mathrm{CH}\left(\mathrm{CH}_{2}\right)_{7} \mathrm{COOH}$.

\section{Results and Discussion}

\subsection{Epoxidation and Esterification}

In our earlier studies on the synthesis of diesters we described the treatment of epoxidized oleic acid with appropriate fatty acids in the presence of catalytic p-toluenesulfonic acid (PTSA) to yield various ring opened products [10]. The process was followed by the esterification of carboxylic acid group with n-butanol to afford diester products, and to finish by esterification of the resulting $\alpha$-hydroxy group in diester with oleic and to give triester. All synthesized compounds were verified by FTIR 
spectroscopy.

In the FTIR spectra of compounds mono-, di-, and triester, the absorption due to the $\mathrm{C}-\mathrm{O}$ of epoxy group (822 and 842 $\mathrm{cm}-1)$ is not observed. This fact suggests that the EQA undergoes complete ring opening under the reaction condition. Bands representing $\mathrm{C}=\mathrm{O}$ groups $(725,1743$ cm-1 ), $\mathrm{CH} 3$ groups $(1370-1463 \mathrm{~cm}-1), \mathrm{OH}$ groups (3473-3444 cm-1) and also $\mathrm{C}-\mathrm{O}-\mathrm{C}$ bands in esters (999-1105 cm-1) are clearly visible in the spectra.

The preparation of butyl 9-(octadecanoyloxy) 10-(acyloxy) octadecanoate from EOA is an effective way of introducing branching onto the fatty acid (FA) chains of plant oils.

In situ epoxidation of vegetable oil with carboxylic acid in the presence of suitable catalyst in which peracetic acid formation is an acid-catalyzed reaction [11].

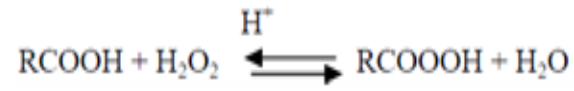

Whereas the main reaction involving the epoxy group formation is an uncatalyzed reaction [12]:

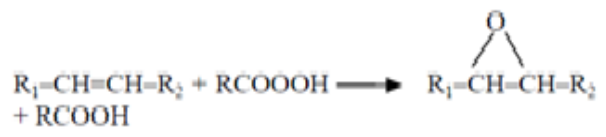

The excess reagents can react with the epoxy rings to cause unwanted side reactions [13] as depicted below:

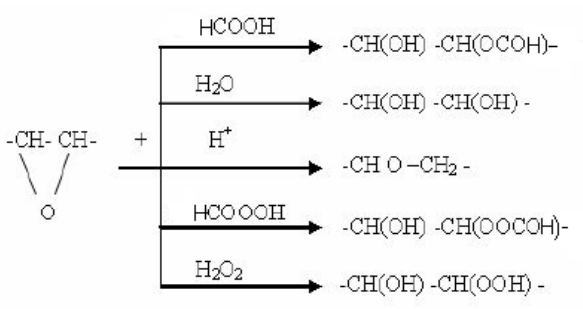

Figure 2. Epoxidation Side Reactions

By analyzing the FTIR spectra of the acid 9, 10-epoxyoctadecanoïc and in comparison with that of the olive oil one will realize the appearance of two new peaks to $846 \mathrm{~cm}^{-1}$ and $919 \mathrm{~cm}^{-1}$. These new peaks testify to the presence of the epoxy function in the product.

In the second step of the synthesis we took advantage of the high reactivity of the epoxide function to graft a long carbon chain, in fact the opening of the oxirane ring in the presence of palmitic acid allows us to have at the end of the reaction product having a relatively high number carbones. On the FTIR spectra we can clearly see the disappearance of the peaks of the epoxide function $\left(846 \mathrm{~cm}^{-1}\right.$ and $\left.919 \mathrm{~cm}^{-1}\right)$ and the appearance of a sizeable peak to $1106 \mathrm{~cm}^{-1}$. Latter corresponds to the ester formed after graft palmitic acid at the oxirane group. The appearance of another peak at 3435 $\mathrm{cm}^{-1}$, it corresponds to the hydroxyl groups $(-\mathrm{OH})$ appears after ring opening.
For the synthesis of diester BHYAOD was performed esterification between $n$-butanol and the product of the second reaction HYAODA. During this reaction we seek grafting onto the carboxyl function of the previous product HYAODA, a butyl group, and this explains the decrease in absorbance of the carboxyl group at $1734 \mathrm{~cm}^{-1}$ and the increase of the peak corresponding to the ester to $1102 \mathrm{~cm}^{-1}$.

The synthesis of triester consists in grafting a carboxyl group on the hydroxyl function of the preceding product the BHYAOD. For that one carries out an esterification between the BHYAOD and another molecule of oleic acid. This reaction can also be carried out by acylation [14].

It should be noted that this spectrum on the total disappearance of peaks corresponding to the double bonds which were $1238 \mathrm{~cm}^{-1}, 1746 \mathrm{~cm}^{-1}$ and $3005 \mathrm{~cm}^{-1}$ thus increase in absorbance of the ester function to $1204 \mathrm{~cm}^{-1}$ and that the decrease of the hydroxyl function at $3443 \mathrm{~cm}^{-1}$ "Fig.3" confirms that the reaction occurred.

The Figure 3 presents the FTIR spectra of the antioxidant additive.

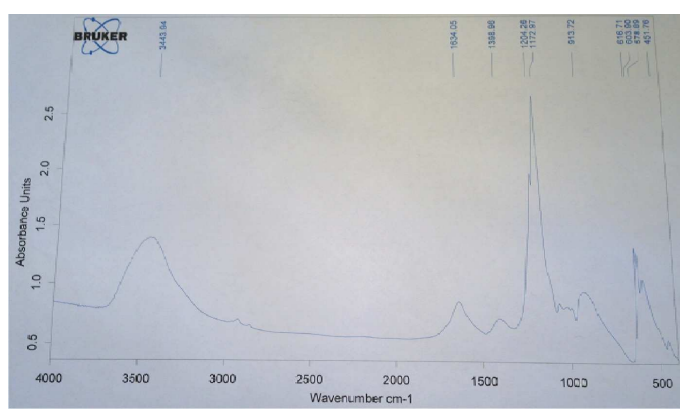

Figure 3. FTIR spectra of triester additive.

\subsection{Test of the Effectiveness of Antioxidant Additive on the Diesel Fuel}

To follow the peroxides value in the diesel before and after the application of our antioxidant additive with various concentrations, we carried out Accelerated Oxidation Test on: diesel without additive (blank) ; commercial diesel; diesel with $2000 \mathrm{ppm}$ of the additive diesel with $4000 \mathrm{ppm}$ of the additive and diesel with $6000 \mathrm{ppm}$ of the additive.

Ultraviolet - visible spectroscopy analysis methods are fast becoming workhorse techniques for providing analytical data on degradation of diesel [8]. The Figures 4-6 show UV-vis of commercial diesel; diesel in the absence and presence of the antioxidant additive at different times of oxidation: $0,1,2,3,4,5$ and 6 hours.

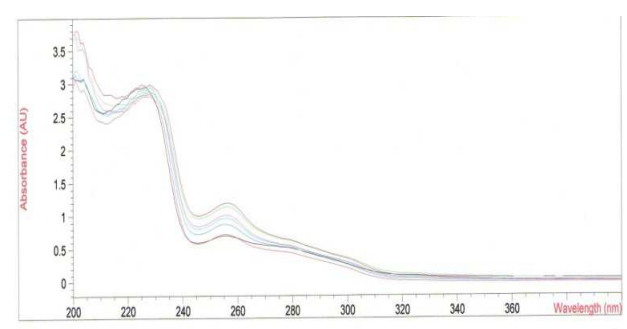

Figure 4. UV-vis of commercial diesel at different times of oxidation. 


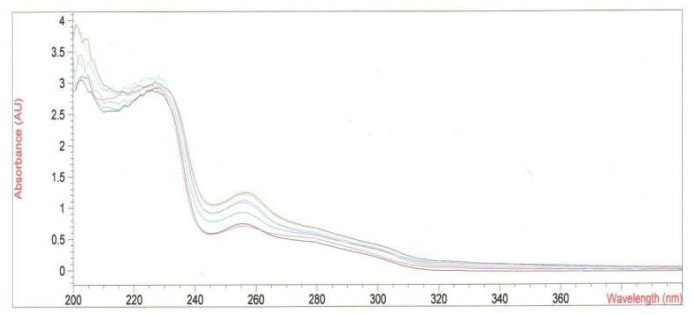

Figure 5. UV-vis of diesel in absence of the additive at different times of oxidation.

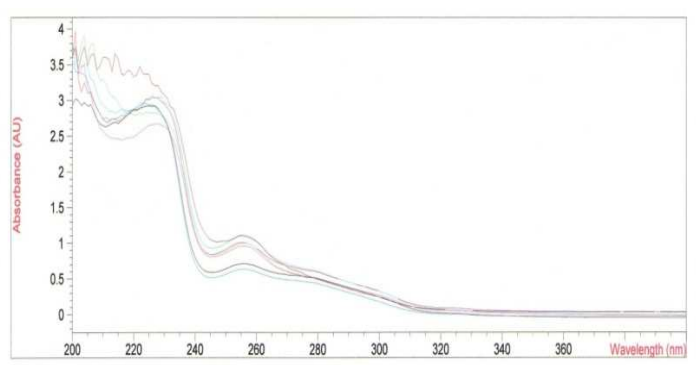

Figure 6. UV-vis of diesel in presence of additive (2000 ppm) at different times of oxidation.

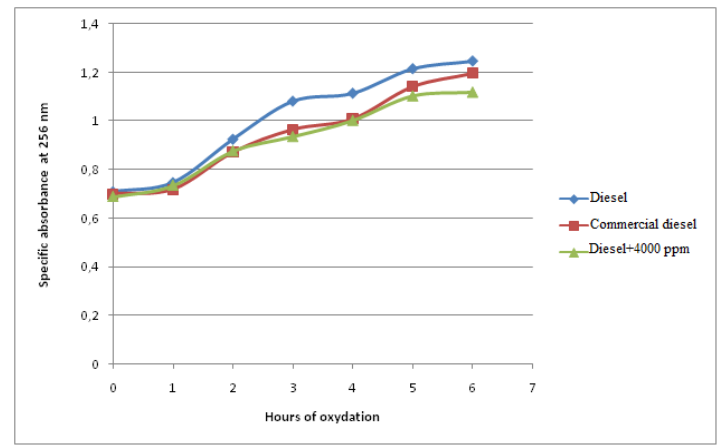

Figure 7. Specific absorbance at $256 \mathrm{~nm}$ of diesel, commercial diesel and diesel +4000 ppm at different times of oxidation.

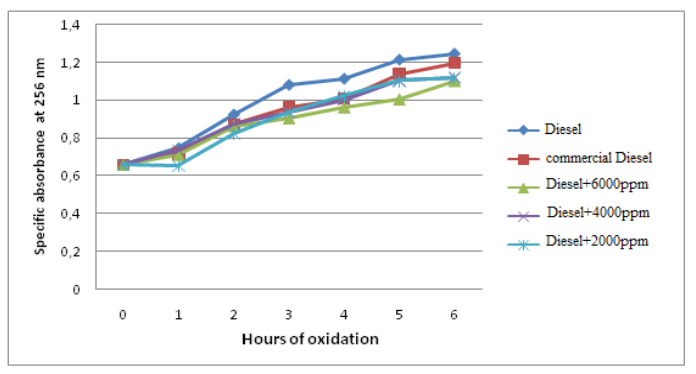

Figure 8. Specific absorbance at $256 \mathrm{~nm}$ of diesel at different times of oxidation and its formulations.

According to the UV-vis spectroscopy data, it is noteworthy that this technique can supply indications about quality of diesel and its oxidation products derived from accelerated oxidation test (AOT). This UV-vis spectroscopy determination constitutes a different approach from the measure of primary and secondary oxidation products, for example, peroxides, ketones, acid, aldehydes and others, and actually, it has been adopted more and more. In this direction, one supervised the Absorbance at $256 \mathrm{~nm}$ of diesel at different times of oxidation. Comparing the spectrum of diesel with $2000 \mathrm{ppm}$ additive and the blank we will notice a clear reduction in the peroxide value but the comparison of diesel with $2000 \mathrm{ppm}$ antioxidant and the commercial one show that they have the same results.

The Figures 4-8 showed that the samples have an absorption pick at $256 \mathrm{~nm}$. The Figure 5 showed UV-vis spectrum of diesel in absence of additive with absorbance at $232 \mathrm{~nm}$ from $0,65962(0 \mathrm{~h}$ of oxidation) to 1,24540 ( $6 \mathrm{~h}$ of oxidation). From Figures 7-8 it was found that after addition of antioxidants to the diesel with various concentration of 2000-4000 and $6000 \mathrm{ppm}$, this last become more stable than the blank.

We can observe these results very clearly even on the coloring level of diesel in the "Fig. 9", we have of left on the right: commercial Diesel, Diesel with $2000 \mathrm{ppm}$, Diesel with $4000 \mathrm{ppm}$ and finally Diesel with $6000 \mathrm{ppm}$.

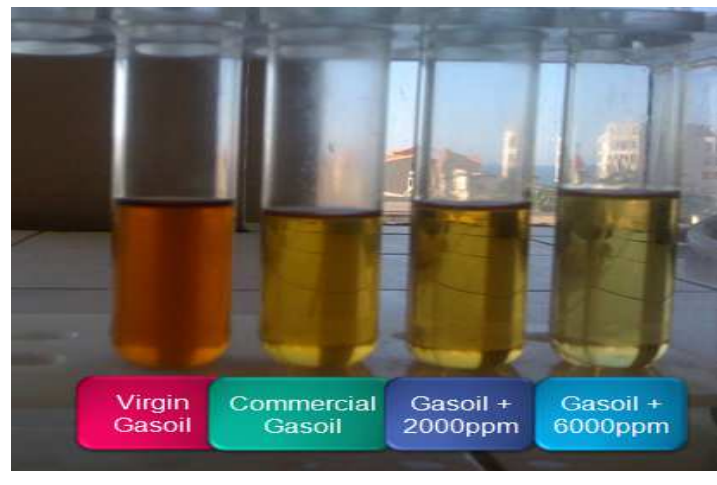

Figure 9. Colouring of Diesel oil after the tests with oxidation.

\section{Conclusion}

In this work, an antioxidant additive for diesel fuel was synthesized. We sought to enhance the inedible vegetable oils, in our case it was the bitter olive oil, but we can soon do tests on waste oils such as frying oils. The products obtained at the different synthesis stages were characterized by FTIR spectroscopy.the yields obtained in these steps are interesting and relevant bibliographic data. The results showed a clear reduction of the peroxide value which was monitored by UV-visible spectroscopy. Reduction in peroxide content confirms the inhibition of the oxidation phoneme and thus of the good efficiency of the bioadditive synthesized.

\section{Acknowledgements}

The authors acknowledge Naftal Society (Distribution of Algerian Petroleum Products) for their material help.

\section{References}

[1] N.Salih, J.Salimon and E. Yousif, "Synthetic biolubricant basestocks based on environmentally friendly raw materials", Journal of King Saud University - Science (2012) 24, 221-226. 
[2] M.Senthil Kumar, A.Ramesh and B.Nagalingam, "Biomass and bio-energy" (2003) 25, 309.

[3] M.Eissen,J.Metzger,E.Schmidt,U. Schneidewind, "10 years after Rio - Concepts on the contribution of chemistry to a sustainable development, Angew". Chem. Int. Ed (2002) 41, 414-436.

[4] M.Genas, Rilsan (Polyamid 11), "Synthese and Eigenschaften, Angewandte Chemie", (1962)74,535-540.

[5] J.C. Guibet, "Carburants et moteurs: technologies, énergie, environnement", Volume 1 (1994).

[6] D.Chaithongdee,J.Chutmanop,P.Srinophakun, "Effect of Antioxidants and Additives on the Oxidation Stability of Jatropha Biodiesel". Kasetsart Journal - Natural Science (2010) 44, 243-50.

[7] M.L.A.Tavares, N.Queiroz,I.M.G .Santos, A. L.Souza,E. H. S.Cavalcanti, A. K. D. Barros, R.Rosenhaim, L. E. B.Soledade, A. G. Souza, "Sunflower Biodiesel. Use of P-DSC in the Evaluation of Antioxidant Efficiency". Journal of Thermal Analysis and Calorimetry (2011) 106(2), 575-9.

[8] L. R.Almeida, A. L.Silva, F. H. N.Souza, A. A. Hidalgo, M. L.Vega, H. N.Cunha, M. A. S. Rios, "Evaluation of Antioxidant Potentiality of Compounds Derived from Biomass for Application in Biodiesel from Soybean Oil”, Química no Brasil, (2011).
[9] H. N. Fernando Souza, R.de Almeida Layane, C. L. Batista Francisco Samuel, Alexsandra de S. Rios Maria, "UV-Visible Spectroscopy Study of Oxidative Degradation of Sunflower Biodiesel",CSCanada Energy Science and Technology Vol. 2, (2011), pp. 56-61.

[10] J.Salimon, N.Salih, E.Yousif, "Chemically modified biolubricant basestocks from epoxidized oleic acid: Improved low temperature properties and oxidative stability",Journal of Saudi Chemical Society (2011) 15, 195-201.

[11] Tayde Saurabh., M.b.Patnaik, S.L. Bhagt, V.C. Renge, "Epoxidation of vegetable oils", International journal of advanced engineering technology, a review (2011) 0976-3945.

[12] Z.S.Petrovic, A. Zlatanic, C.C. Lava, S. Sinadinovicfise, "Epoxidation of soya bean oil in toluene with peroxoacetic acid and peroxoformic acids-kinetics and side reactions". European Journal of Lipid Science and Technology (2002). 104(5):293-299.

[13] S.F.Snezana, J.Milovan, S.P.Zoran. "Kinetics of in situ Epoxidation of Soybean Oil in Bulk Catalyzed by Ion Exchange Resin" JAOCS, Vol1, (2001). 78, no. 7

[14] N. Salih, J. Salimon, E. Youcef, "Synthesis of oleic acid based esters as potential basestock for biolubricant production". Turkish J. Eng. Env. Sci. (2011) 35, 115 - 123. 